\title{
Gains of Chromosome 1p and 15q are Associated with Poor Survival After Cytoreductive Surgery and HIPEC for Treating Colorectal Peritoneal Metastases
}

\author{
Malin Enblad, MD, $\mathrm{PhD}^{1}$ (D), Wilhelm Graf, MD, $\mathrm{PhD}^{1}$, Alexei Terman, MD, $\mathrm{PhD}^{2}$, Pascal Pucholt, $\mathrm{PhD}^{3}$, \\ Björn Viklund ${ }^{3}$, Anders Isaksson, $\mathbf{P h D}^{3}$, and Helgi Birgisson, $\mathrm{MD}, \mathbf{P h D}^{1}$ \\ ${ }^{1}$ Department of Surgical Sciences, Colorectal Surgery, Uppsala University, Uppsala, Sweden; ${ }^{2}$ Department of \\ Immunology, Genetics and Pathology, Experimental Pathology, Uppsala University, Uppsala, Sweden; ${ }^{3}$ Department of \\ Medical Sciences, Science for Life Laboratory, Uppsala University, Uppsala, Sweden
}

\begin{abstract}
Purpose. Genetic alterations in colorectal peritoneal metastases (PM) are largely unknown. This study was designed to analyze whole-genome copy number alterations (CNA) in colorectal PM and to identify alterations associated with prognosis after cytoreductive surgery (CRS) and hyperthermic intraperitoneal chemotherapy (HIPEC).

Methods. All patients with PM, originating from a colorectal adenocarcinoma, who were treated with CRS and HIPEC in Uppsala Sweden, between 2004 and 2015, were included $(n=114)$. DNA derived from formalin-fixed paraffin-embedded (FFPE) specimens were analyzed for CNA using molecular inversion probe arrays.
\end{abstract}

Poster presentation at 11th International Workshop on Peritoneal Surface Malignancy 2018, Paris, France.

A previous version of the manuscript was included in the corresponding author's doctorial thesis with the title: Colorectal and appendiceal peritoneal metastases - From population studies to genetics.

Electronic supplementary material The online version of this article (https://doi.org/10.1245/s10434-019-07923-6) contains supplementary material, which is available to authorized users.

(C) The Author(s) 2019

First Received: 30 April 2019;

Published Online: 16 October 2019

M. Enblad, MD, PhD

e-mail: malin.enblad@surgsci.uu.se
Results. There were extensive but varying degrees of CNA, ranging from minimal CNA to total aneuploidy. In particular, gain of parts of chromosome 1p and major parts of $15 q$ were associated with poor survival. A combination of gains of $1 \mathrm{p}$ and $15 \mathrm{q}$ was associated with poor survival, also after adjustment for differences in peritoneal cancer index and completeness of cytoreduction score [hazard ratio (HR) 5.96; 95\% confidence interval (CI) 2.19-16.18]. These patients had a mean copy number (CN) of 3.19 compared with 2.24 in patients without gains. Complete $\mathrm{CN}$ analysis was performed in 53 patients. Analysis was unsuccessful for the remaining patients due to insufficient amounts of DNA and signals caused by interstitial components and normal cells. There was no difference in survival between patients with successful and unsuccessful $\mathrm{CN}$ analysis.

Conclusions. This study shows that gains of parts of chromosome $1 p$ and of major parts of chromosome $15 q$ were significantly associated with poor survival after CRS and HIPEC, which could represent future prognostic biomarkers.

Despite improved treatment with cytoreductive surgery (CRS) and hyperthermic intraperitoneal chemotherapy (HIPEC) for colorectal peritoneal metastases (PM), a significant proportion of patients experience rapid disease recurrence and have limited benefit of the treatment. At present, patient selection for CRS and HIPEC is based on absence of haematogenous spread, resectable PM during surgery, peritoneal cancer index (PCI), and the patients ability to withstand major surgery. ${ }^{1}$ Although PCI is a strong prognostic factor, the macroscopic tumor growth 
judged by the surgeon does not always correlate to microscopic tumor growth, and low PCI does not always imply a favorable prognosis. ${ }^{2-4}$

A novel approach in the rapidly progressing field of PM therefore might be to identify prognostic and predictive molecular biomarkers. Little is known about genetic alterations associated with peritoneal dissemination in colorectal cancer. ${ }^{5}$ In colorectal cancer, chromosomal instability leads to frequent deletions and amplifications throughout the genome causing allelic imbalances and copy number alterations (CNA). ${ }^{6}$ Studies on PM and CNA are scarce, but Diep et al. ${ }^{7}$ demonstrated a larger number of CNAs in peritoneal and liver metastases compared with primary tumors. There also were differences concerning which part of the genome that was affected. This suggests that CNA could play an important role in PM, which needs further evaluation. The purpose of this study were to explore genome-wide CNA in colorectal PM and to identify alterations associated with prognosis in patients treated with CRS and HIPEC.

\section{MATERIALS AND METHODS}

\section{Patients and Follow-Up}

Between January 2004 and December 2015, 612 patients with PM were scheduled for initial CRS and intraperitoneal chemotherapy at Uppsala University Hospital, Sweden. Patients with inoperable disease $(n=76)$, debulking surgery $(n=50)$, no macroscopic tumor $(n=8)$, and patients receiving sequential postoperative intraperitoneal chemotherapy $(n=38)$ were excluded. Patients with lowgrade appendiceal mucinous neoplasms $(n=118)$, noncolorectal primary tumors $(n=108)$, lacking neoplastic epithelium in surgical specimens from CRS $(n=41)$, and patients with pseudomyxoma peritonei $(n=51)$ also were also excluded leaving 122 patients with colorectal and appendiceal PM available for analysis. ${ }^{8,9}$ Appendiceal tumors were excluded after analysis due to different biology of these tumors and few cases. Baseline variables were retrieved from the medical records, and information about death was recorded from the Swedish population registry (last follow-up February 2017). The study was approved by the regional ethics committee of Uppsala County, Sweden (Dnr 2015/396).

\section{Cytoreductive Surgery and HIPEC}

CRS included peritonectomies, combined with omentectomy and removal of disease-affected organs, as previously described. ${ }^{10}$ HIPEC was performed according to the Coliseum method and was administered for 30-90 min depending on the chemotherapeutic agent used. ${ }^{11}$ The patients had to have adequate renal, liver, and hematopoietic function and WHO performance status of $\leq 2$ to be accepted for CRS and HIPEC. The PCI (range 1-39) was used to quantify the extent of macroscopic tumor load in the abdominal cavity at the beginning of surgery. ${ }^{1}$ The completeness of cytoreduction score (CCS) was used to assess the amount of remaining tumor after CRS. ${ }^{1}$

\section{Histopathology and DNA Preparation}

Surgical specimens were fixed in $4 \%$ buffered formaldehyde and embedded in paraffin, sliced into 3- to 4- $\mu \mathrm{m}$ sections, and stained with haematoxylin and eosin. An experienced gastrointestinal pathologist (A.T.) reviewed the specimens and identified regions of PM with the maximum tumor cell content. DNA was extracted from $10-\mu \mathrm{m}$ thin sections of these regions using QIAamp ${ }^{\circledR}$ FFPE Tissue Kit (QIAGEN) according to the manufacturer's recommendations. DNA was quantified using Qubit ${ }^{\circledR}$ dsDNA HS Assay Kit (Thermo Fisher Scientific). Samples with low concentration of DNA were concentrated using MinElute ${ }^{\circledR}$ Reaction Cleanup Kit (50) (QIAGEN).

\section{OncoScan ${ }^{\circledR}$}

The array analysis was performed according to standard protocols for Affymetrix OncoScan ${ }^{\circledR}$ Arrays (Affymetrix OncoScan ${ }^{\circledR}$ FFPE Assay Kit User Guide (P/N 703175 Rev.2), Affymetrix Inc., Santa Clara, CA). Briefly, $80 \mathrm{ng}$ of total genomic double-stranded DNA was incubated for annealing of molecular inversion probes. ${ }^{12-14}$ The gaps formed after the annealing-process were filled with dNTPs followed by DNA amplification through two consecutive steps of PCR. The samples were prepared for hybridization onto the OncoScan ${ }^{\circledR}$ Array after digestion with the HaeIII enzyme. Hybridized probes were bound to streptavidinphycoerythrin conjugates using GeneChip ${ }^{\circledR}$ Fluidics Station 450 (Affymetrix Inc.), and arrays were scanned using GeneChip ${ }^{\circledR}$ Scanner 3000 7G (Affymetrix Inc.).

\section{Data Analysis and Statistics}

Microarray data were normalized using Affymetrix OncoScan console 1.3 and segmented using BioDiscovery Nexus Copy Number 8.0 with the TuScan algorithm and default settings. Analyses of allele-specific copy numbers (CN) and average ploidy were performed using Tumor Aberration Prediction Suite (TAPS) ${ }^{15}$ TAPS also was used to calculate frequencies of CNA (gain to $>2$ copies per cell, loss to $<2$ copies per cell) in the population and for 
short term ( $\leq 2$ years) and long term ( $\geq 2$ years) survivors over the whole genome.

Correlation between CNA status in each segment of $10 \mathrm{Mbp}$ and survival probability was calculated using logrank test. To correct for multiple testing and difference in sensitivity of the log-rank test for different group sizes, permutation testing with 50,000 replicates was used to determine the distribution of the smallest $p$ value when randomly assigning the patients of the study population into groups based on simulated genome segments. This distribution of extreme $p$ values was then used to calculate empirical $p$ values for actual genomic segments. ${ }^{16,17}$

Multivariate Cox proportional hazard regression was used to determine the relative contribution to hazard models of gain of prognostically significant segments of chromosome 15,1 , both 1 and 15 , mean $\mathrm{CN}>2.5$, age, gender, preoperative chemotherapy, signet ring and mucinous histopathology, high PCI $(\geq 18)$ or low PCI $(<18)$, and CCS 0 or 1 and CEA (carcinoembryonic antigen). ${ }^{18}$ Descriptive data were presented as median with interquartile range if not otherwise specified. The Fisher's exact test was used to compare proportions, and the MannWhitney $U$ test was used to compare continuous data of two groups. Statistical analyses were performed with $\mathrm{R}$ version 3.1.4 ( $\mathrm{R}$ foundation for Statistical Computing, Vienna, Austria), when not performed with TAPS.

\section{RESULTS}

\section{Patients and Follow-Up}

Of the initial 122 patients, 114 fulfilled the inclusion criteria after review of histopathological examinations. Patients were excluded because of other primary tumor origin (gastric cancer and breast cancer, $n=2$ ) or if no neoplastic epithelium were found in the specimens $(n=6)$. $\mathrm{CN}$ analysis was successful in 53 patients. Analysis was unsuccessful because of inability to extract sufficient amounts of DNA from the specimens $(n=13)$, signals caused by interstitial components, and noncancer cells or insufficient amounts of DNA for CN analysis $(n=48)$. Patients with unsuccessful analysis were more likely to have appendiceal cancer, synchronous PM, mucinous and signet ring histopathology, male gender, lower PCI, and lower CEA (Supplementary Table 1). There was no difference in overall survival between patients with successful and unsuccessful $\mathrm{CN}$ analysis ( $p=0.676$, Supplementary Fig. 1). CN analyses of appendiceal PM were successful in nine of ten cases due to low tumor cell content. The only patient with appendiceal cancer and successful $\mathrm{CN}$ analysis was excluded, leaving 52 patients with colorectal PM for final analysis.

\section{Copy Number Alterations}

The frequency of $\mathrm{CN}$ gain or loss at each position is shown in Fig. 1. Overall, there was extensive CNA affecting large proportions of the genome. Gain was more common than loss and frequently affected chromosomes 1q, 2p/q, 5p, 7p/q, 8q, 12p/q, 13q, 16p, and 20p/q. Losses were common in chromosome $1 \mathrm{p}, 4 \mathrm{p} / \mathrm{q}, 8 \mathrm{p}, 15 \mathrm{q}, 17 \mathrm{p} / \mathrm{q}$, $18 \mathrm{p} / \mathrm{q}$, and $22 \mathrm{q}$. Limited tumor heterogeneity was observed in approximately $10 \%$ of the samples.

\section{Prognosis and Copy Number Alterations}

When the population was divided into short-term ( $\leq 2$ years) and long-term survivors ( $>2$ years) after CRS and HIPEC and compared with respect to frequency of $\mathrm{CN}$, short-term survivors had an overall higher frequency of gains. Gain of parts of chromosome 1p and a majority of chromosome $15 \mathrm{q}$ were associated with short-term survival (Fig. 2a, $p \leq 0.005$ ). There were no significant losses associated with survival (Supplementary Fig. 2).

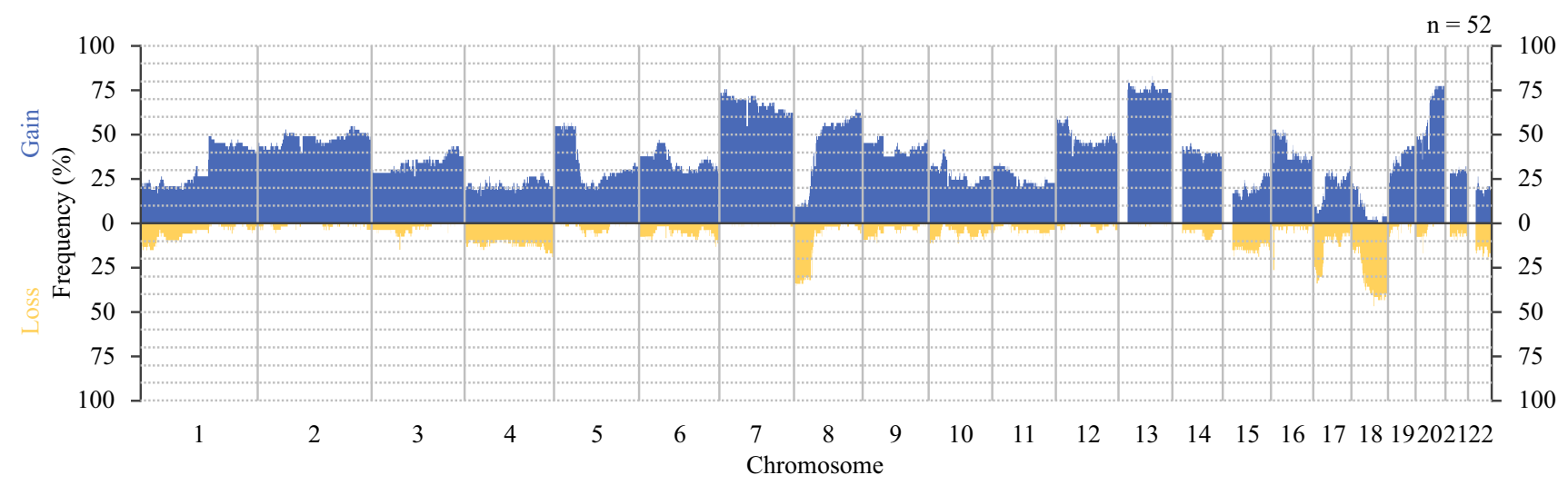

FIG. 1 The copy number frequency at each position for all 52 samples. Blue indicates three or more copies. Yellow indicates one or less copies 


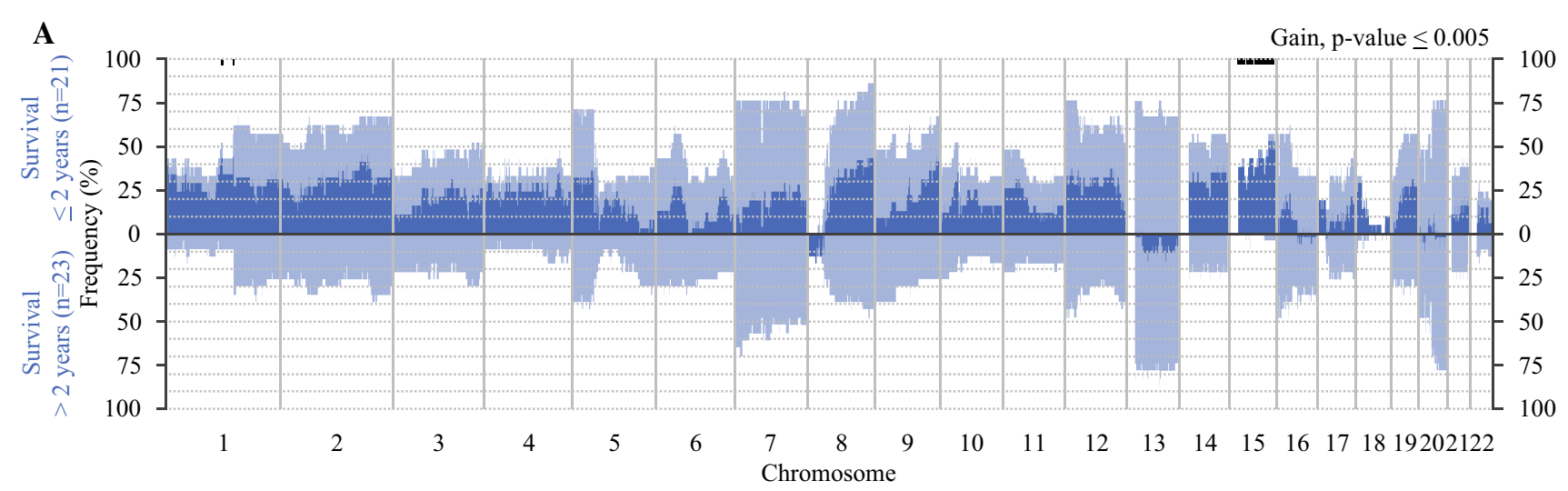

B

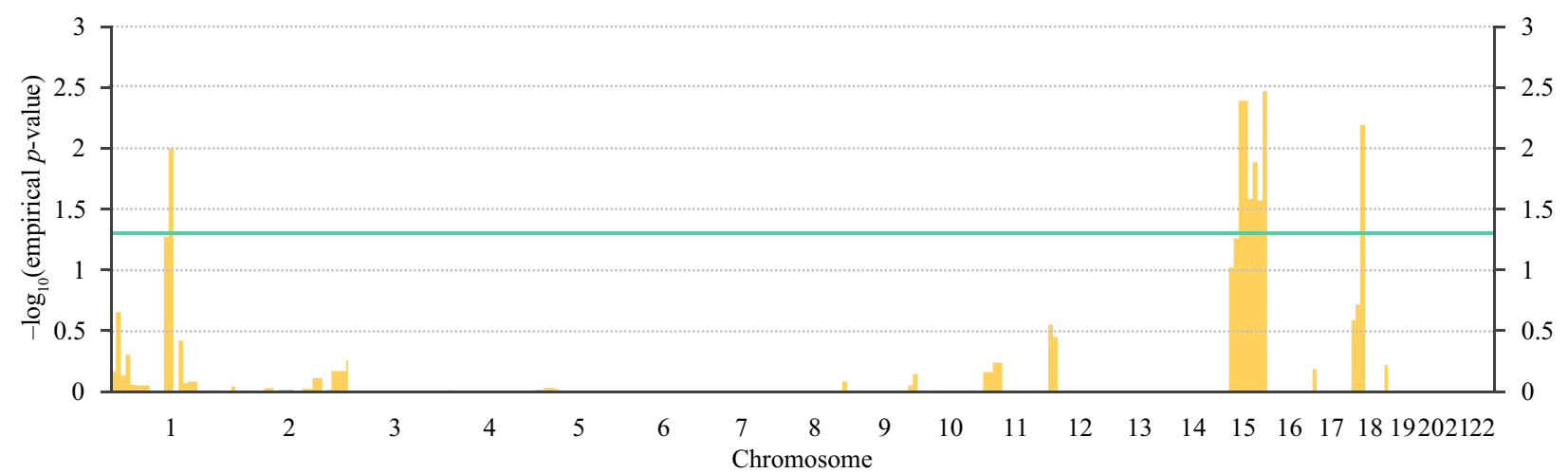

C

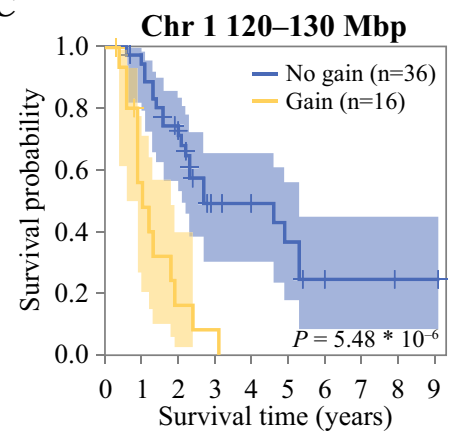

Number at risk

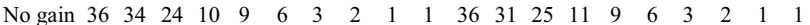
Gain $16 \begin{array}{lll}16 & 2 & 1\end{array}$

FIG. 2 a Comparison of copy number frequency of gain between short term survivors ( $\leq 2$ years, top part) and long term survivors ( $>2$ years, lower part). Light blue is the frequency for each sample and dark blue is the difference. The black bars are regions with $p \leq 0.005$. b Probability of association between gain within segments of $10 \mathrm{Mbp}$ and difference in survival. Values are given as empirical $p$ values. Green line is empirical $p=0.05$. c Comparison of survival

In an alternative approach, the population was separated by $\mathrm{CN}$ status in all $10-\mathrm{Mbp}$ segments of the genome and analyzed with log-rank test. After correcting for multiple comparisons and using empirical $p$ values, gains of parts of chromosome $1 \mathrm{p}$ (region 120-130 Mbp) and 18p (region 20-30 Mbp) and gain of major parts of chromosome $15 q$ (region 40-103 Mbp) was associated with shorter survival
D
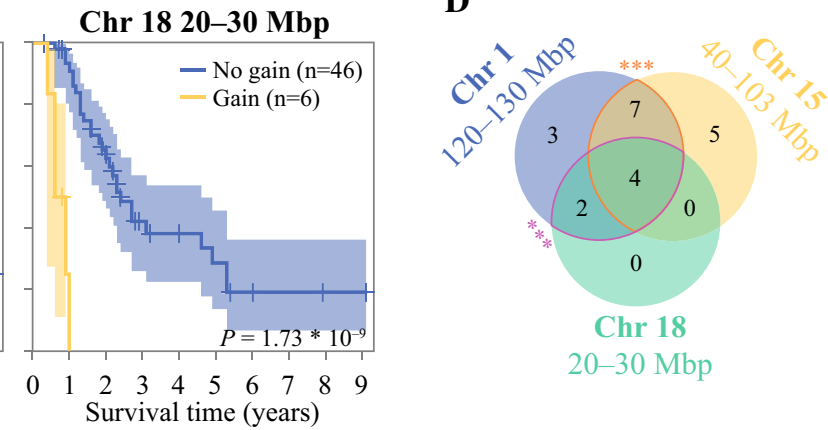

$\begin{array}{llllllllll}46 & 40 & 26 & 11 & 9 & 6 & 3 & 2 & 1 & 1\end{array}$ $6 \quad 1$

probability in patients with or without gain within any 10-Mbp segment of chromosome 1 (120-130 Mbp), chromosome 15 (40 and $103 \mathrm{Mbp}$ ), and chromosome 18 (20-30 Mbp). d Number of samples with gain in any of the focal regions or in a combination of them. There was a significant association between gains of chromosome 15 and $1(p=0.002)$ as well as between gains of chromosome 1 and 18 $(p=0.0004)$. Chr chromosome

(Fig. 2b, empirical $p$ value $<0.05$ ). The survival probability in patients with and without gain of these regions on chromosome 1p, 15q, and 18p are illustrated in Fig. 2c. Gain of chromosome $18 \mathrm{p}$ was found only in patients that also had gain of $1 \mathrm{p}$ (Fig. 2d). In addition, a significant association between gains of both $1 p$ and $15 q(p=0.002)$ and of both $1 \mathrm{p}$ and $18 \mathrm{p}(p=0.0004)$ was found. The region 
TABLE 1 Baseline characteristics of patients with colorectal peritoneal metastases and successful copy number analysis $(n=52)$, stratified by the presence of gain of

chromosome 15 , chromosome

1 , both chromosome 1 and 15 , and no gain

\begin{tabular}{|c|c|c|c|c|}
\hline & $\begin{array}{l}\text { Gain Chr1 } \\
n(\%)\end{array}$ & $\begin{array}{l}\text { Gain Chr15 } \\
n(\%)\end{array}$ & $\begin{array}{l}\text { Gain Chr1\&15 } \\
n(\%)\end{array}$ & $\begin{array}{l}\text { No gain } \\
n(\%)\end{array}$ \\
\hline Total & $16(100)$ & $16(100)$ & $11(100)$ & $31(100)$ \\
\hline \multicolumn{5}{|l|}{ Gender } \\
\hline Male & $7(44)$ & $7(44)$ & $5(45)$ & $11(35)$ \\
\hline Female & $9(56)$ & $9(56)$ & $6(55)$ & $20(65)$ \\
\hline Age (median IQR) & $55(47-65)$ & $56(46-63)$ & $57(46-65)$ & $60(54-67)$ \\
\hline \multicolumn{5}{|l|}{ Primary tumor } \\
\hline Right colon & $7(44)$ & $9(56)$ & $6(55)$ & $16(52)$ \\
\hline Left colon & $9(56)$ & $7(44)$ & $5(45)$ & $10(32)$ \\
\hline Rectum & $0(0)$ & $0(0)$ & $0(0)$ & $5(16)$ \\
\hline \multicolumn{5}{|l|}{ Diagnosis of PM } \\
\hline Synchronous $^{\mathrm{a}}$ & $9(56)$ & $10(63)$ & $7(64)$ & $16(52)$ \\
\hline Metachronous & $7(44)$ & $6(38)$ & $4(36)$ & $15(48)$ \\
\hline Preop. Chemo. & $9(56)$ & $8(50)$ & $6(46)$ & $23(74)$ \\
\hline \multicolumn{5}{|l|}{ Histopathology } \\
\hline Mucinous PM & $9(56)$ & $11(69)$ & $8(73)$ & $14(45)$ \\
\hline Signet ring $\mathrm{PM}$ & $2(13)$ & $4(25)$ & $2(18)$ & $2(6)$ \\
\hline PCI (median IQR) & $20(15-24)$ & $21(18-24)$ & $21(18-24)$ & $15(10-22)$ \\
\hline \multicolumn{5}{|l|}{ CCS } \\
\hline $\mathrm{CC}-0$ & $14(88)$ & $13(81)$ & $9(82)$ & $29(94)$ \\
\hline $\mathrm{CC}-1$ & $2(13)$ & $3(19)$ & $2(18)$ & $2(6)$ \\
\hline CEA (median IQR) & $33(7-103)$ & $14(4-67)$ & $39(8-92)$ & $12(4-39)$ \\
\hline Haematog.met. ${ }^{\mathrm{b}}$ & $3(19)$ & $2(13)$ & $1(9)$ & $3(7)$ \\
\hline
\end{tabular}

Values are number of cases with percentage in parentheses if not otherwise specified

$C C S$ completeness of cytoreduction score, $C h r$ chromosome, $C N$ copy number, IQR interquartile range, $P C I$ peritoneal cancer index, $P M$ peritoneal metastases

${ }^{a}$ Diagnosis of PM within 6 months of primary tumor diagnosis

${ }^{b}$ Diagnosis of haematogenous metastasis before or at time of diagnosis of PM of gain of chromosome $1 \mathrm{p}$ included the colorectal cancerassociated genes REG4 and NOTCH2 and gain of $15 \mathrm{q}$ included the genes MAP2K1, SMAD3, SMAD6, and $I G F I \mathrm{R}$, among others. All patients with gain of $1 \mathrm{p}$ and $15 \mathrm{q}$ had colon cancer and tended to have higher PCI and more often signet ring and mucinous histopathology (Table 1).

There was a wide distribution of genomic composition, ranging from minimal CNA (diploid, CN 2) to almost total aneuploidy. Patients with no gain of chromosome $1 p$ or $15 q$ had a mean $\mathrm{CN}$ of 2.24. Patients with either gain of chromosome $1 p$, or both $1 p$ and $15 q$ had a higher mean $\mathrm{CN}$ than patients with no gain (Fig. 3, mean CN 3.12, $p=0.0002$ and mean $\mathrm{CN} 3.19, \quad p=1.9 \times 10^{-6}$ respectively).

The extensive CNA found in patients with gains of $1 \mathrm{p}$ and $15 \mathrm{q}$ indicates whole genome duplication. ${ }^{19}$ Survival probability was lower in patients with mean $\mathrm{CN}>2.5$ (Supplementary Fig. 3, $p=0.0372$ ).

In a multivariate hazard model, gain of chromosome 15 and gains on both chromosome 1 and 15 were independently associated with short survival. A mean $\mathrm{CN}>2.5$ was not an independent prognostic factor. When including clinical variables in the hazard models, the association between poor prognosis and gain of chromosome 15 and gains of both chromosome 1 and 15 remained $\left(p=0.0035\right.$ and $\left.p=8.0 \times 10^{-5}\right)$. PCI, CCS, and CEA also were associated with poor survival, whereas mucinous histopathology was associated with longer survival (Table 2).

\section{DISCUSSION}

In this study, colorectal PM had CNA in abundance, and gains of parts of chromosome $1 \mathrm{p}$ and major parts of chromosome $15 q$ were independently associated with poor prognosis after CRS and HIPEC. This is the first study to focus on genome-wide CNA in colorectal PM, and a prognostic biomarker may save these patients from unsuccessful surgery and present an opportunity for alternative treatment. 
Copy number

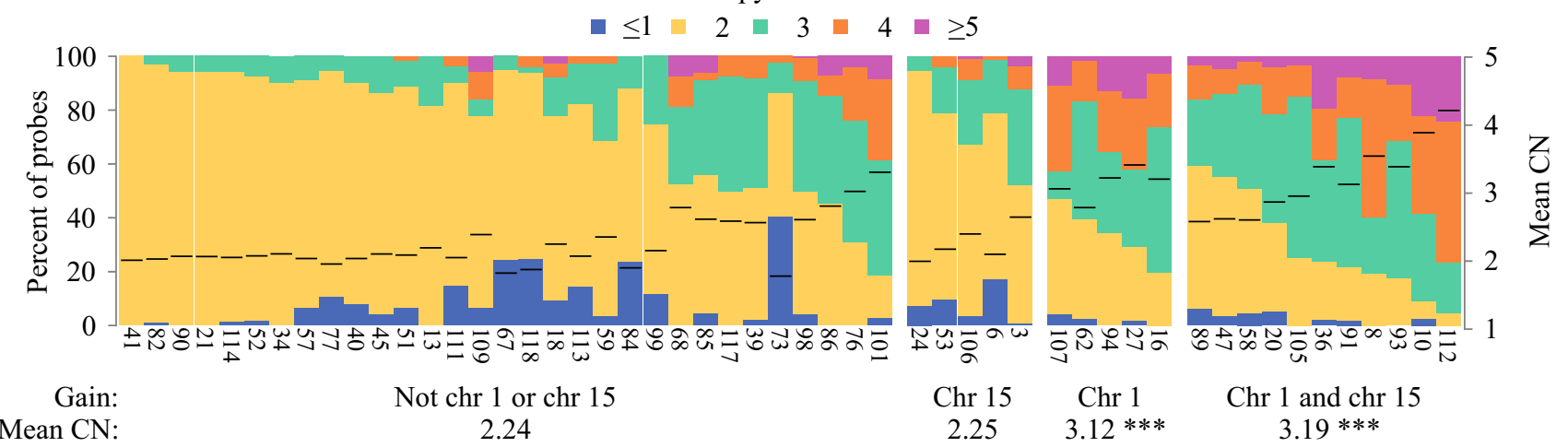

FIG. 3 Percent of probes per copy number for all 52 samples separated by samples with gain of chromosome 15, gain of chromosome 1, gains of both chromosome 1 and 15 , and no gain of 1 or 15 . The copy numbered differed between no gain and gain of chromosome 1 and gains of both chromosome 1 and 15 ( $p=0.0002$ and $p=1.91 \times 10^{-6}$ respectively). Chr chromosome, $C N$ copy number
TABLE 2 Multivariate cox proportional regression analysis of predictors of survival in patients with colorectal peritoneal metastases

\begin{tabular}{|c|c|c|c|}
\hline & Hazard ratio & $95 \%$ confidence interval & $p$ value \\
\hline \multicolumn{4}{|l|}{ Gain } \\
\hline Chromosome 1, not $15^{\mathrm{a}}$ & 2.86 & $0.80-10.2$ & 0.1077 \\
\hline Chromosome 15 , not $1^{\mathrm{b}}$ & 7.42 & $2.28-24.2$ & 0.0009 \\
\hline Chromosome 1 and 15 & 16.39 & $5.66-47.5$ & $2.6 \times 10^{-7}$ \\
\hline \multicolumn{4}{|l|}{ Gain and mean $\mathrm{CN}>2.5$} \\
\hline Chromosome 1, not $15^{\mathrm{a}}$ & 3.08 & $0.68-14.02$ & 0.1460 \\
\hline Chromosome 15 , not $1^{\mathrm{b}}$ & 7.30 & $2.22-24.07$ & 0.0011 \\
\hline Chromosome 1 and 15 & 17.66 & $4.59-67.99$ & $2.9 \times 10^{-7}$ \\
\hline Mean $\mathrm{CN}>2.5$ & 0.90 & $0.29-2.81$ & 0.8569 \\
\hline \multicolumn{4}{|l|}{ Chromosome 15} \\
\hline Gain Chr 15 versus no gain & 5.12 & $1.71-15,32$ & 0.0035 \\
\hline Gender & 1.22 & $0.44-3.36$ & 0.7045 \\
\hline Age & 1.003 & $0.96-1.05$ & 0.9057 \\
\hline Preop. Chemo. & 1.87 & $0.64-5.49$ & 0.2537 \\
\hline Mucinous histopathology & 0.45 & $0.15-1.33$ & 0.1480 \\
\hline Signet ring histopathology & 1.71 & $0.45-6.58$ & 0.4326 \\
\hline PCI. $\geq 18$ versus $<18$ & 9.12 & $2.61-31.91$ & 0.0005 \\
\hline CCS. CC-1 versus CC- 0 & 8.46 & $1.97-36.32$ & 0.0041 \\
\hline CEA & 1.01 & $1.00-1.01$ & 0.0116 \\
\hline \multicolumn{4}{|l|}{ Chromosome 1 and 15} \\
\hline Gain Chr 1 and 15 versus no gain & 10.62 & $3.28-34.36$ & $8.0 \times 10^{-5}$ \\
\hline Gender & 1.80 & $0.63-5.18$ & 0.2761 \\
\hline Age & 1.02 & $0.97-1.07$ & 0.3894 \\
\hline Preop. Chemo. & 3.35 & $1.05-10.62$ & 0.0405 \\
\hline Mucinous histopathology & 0.26 & $0.08-0.84$ & 0.0242 \\
\hline Signet ring histopathology & 0.76 & $0.19-3.06$ & 0.6943 \\
\hline PCI. $\geq 18$ versus $<18$ & 13.38 & $3.28-34.36$ & $5.7 \times 10^{-5}$ \\
\hline CCS. CC-1 versus CC-0 & 13.64 & $3.06-60.79$ & 0.0006 \\
\hline CEA & 1.01 & $1.00-1.01$ & 0.0102 \\
\hline
\end{tabular}

Significant $p$ values $>0.05$ are given in bold

$C C S$ completeness of cytoreduction score, $C N$ copy number, $C h r$ chromosome, $P C I$ peritoneal cancer index ${ }^{\mathrm{a}}$ Gain in any 10-Mbp segment of chromosome 1 (120-130 Mbp) and no gain of chromosome 15

${ }^{\mathrm{b}}$ Gain in any $10 \mathrm{Mbp}$ segment of chromosome 15 (40-103 Mbp) and no gain of chromosome 1 
Colorectal PM had a wide range of CNA ranging from diploid to almost total aneuploidy. Genetic alterations in primary colorectal tumors have been thoroughly described by the Cancer Genome Atlas Network and the most frequent CNAs in the PM resembled those found in primary tumors. However, gains were more common and present for almost all chromosomes and pronounced differences were gain of $2 \mathrm{p} / \mathrm{q}, 5 \mathrm{p}, 12 \mathrm{p}$, and $16 \mathrm{p}$ in the PM. ${ }^{6}$ So far, other comparable studies on colorectal PM and CNA are scarce, but in 2004, Diep et al. ${ }^{7}$ analyzed 10 primary carcinomas, 14 local recurrences, $7 \mathrm{PM}$, and 42 liver metastases using comparative genomic hybridization and observed gains of $5 p$ and $12 p$ more frequently in PM. Kleivi et al. ${ }^{20}$ found increased expression of genes on $5 p$ being more common in PM than in primary tumors and liver metastases. These differences between primary tumors and PM suggests that PM acquire additional genetic alterations and that it is probably not enough to analyze the primary tumor when aiming to predict prognosis or response to therapy. Despite the lack of studies on CNA and PM, there are studies on CNA in relation to events in cancer progression, liver metastases, and overall survival, but the same gain of $1 p$ and $15 q$ has not been described. $^{21,22}$

This study was designed to identify CNA associated with prognosis after CRS and HIPEC when dividing the studied population into short- and long-term survivors, gains of chromosome $1 p$ and $15 q$ were associated with poor prognosis. To avoid conclusions based on dichotomized survival-groups, the genome was divided into 10-Mbp segments and assessed with log-rank test. After multiple testing correction by permutation testing and using empirical $p$ values, gains of $1 \mathrm{p}$ and $15 \mathrm{q}$ were still associated with poor prognosis and so was gain of chromosome $18 \mathrm{p}$. However, gain of $18 \mathrm{p}$ was always combined with gain of chromosome $1 \mathrm{p}$, and interpreted as secondary to alterations of $1 p$. In addition, gains of $1 p$ and $15 q$ also were combined in the majority of cases, which was independently associated with poor prognosis when analyzed together with well-established prognostic factors, such as PCI and CCS.

It is not clear whether chromosomal instability is an initiating event or a consequence of the malignant transformation process. Therefore, it is difficult to predict the effect on tumor suppressors and promoters. However, chromosome $1 \mathrm{p}$ and $15 \mathrm{q}$ harbors many colorectal cancerrelated genes that could play an important prognostic role. To name a few, the affected parts of chromosome 1 include the genes REG4 and NOTCH2. REG4 is involved in cell regeneration and proliferation and is overexpressed in colorectal cancer and its metastases. ${ }^{23}$ Interestingly, it also works as a promoter of gastric PM. ${ }^{24}$ The Notch pathway is involved in epithelial to mesenchymal transition, which eventually leads to migration of cancer cells. ${ }^{25}$ However, increased $\mathrm{NOTCH} 2$-expression has been associated with a favorable prognosis. ${ }^{26}$ Almost the entire chromosome $15 \mathrm{q}$ was affected, including MAP2K1, SMAD3, SMAD6, and $I G F 1 R$. Dysfunctional SMAD-protein leads to ineffective TGF $\beta$-signaling and tumor growth. ${ }^{6,27}$ IGF1R is known to be overexpressed in colorectal cancer, and its activation initiates the well-established MAPK (including MAP2K1) and PI3-K pathways in colorectal cancer. Finally, inhibition of IGF1R is one of the targets of upcoming anticancer drugs. ${ }^{28}$

Patients with gains of $1 \mathrm{p}$ and $15 \mathrm{q}$ had an average $\mathrm{CN}>2.5$, indicating whole genome duplication, which is a frequent event in colorectal cancer. ${ }^{19,29}$ Survival probability was found to be decreased for patients with $\mathrm{CN}>2.5$ but was not an independent prognostic factor. Theoretically, gains of $1 p$ and $15 q$ could be the result of losses in other regions but not in $1 p$ and $15 q$ after whole genome duplication. However, the mechanism behind gains of $1 p$ and $15 \mathrm{q}$ remains unknown.

This study has limitations that have to be mentioned. First, $<50 \%$ of included samples were successfully analyzed, due to insufficient amounts of DNA and signals caused by interstitial components and normal cells. In addition, only one sample per patient were analyzed, and we were therefore not able to analyze intersample heterogeneity. The method is therefore dependent on tumor composition and not ideal for routine analysis of PM specimens. However, there was no difference in survival between successfully and unsuccessfully analyzed samples, which was relevant, because the goal of the study was to explore genetic alterations and to identify alterations associated with prognosis. That being said, the method is feasible for an exploring analysis, but a future validation is desirable. Second, the risk of multiple comparisons is inevitable with high-resolution genome-wide analyses, but correction was made as described above. Third, the studied population was small and pooled towards aggressive disease when excluding Pseudomyxoma peritonei, thus not entirely representative of the heterogeneous group of peritoneal dissemination. However, the studied population represents patients with the greatest need of prognostic and predictive molecular biomarkers.

In conclusion, this study described the extensive but varying CNA in colorectal PM. Gains of parts of chromosome $1 p$ and of major parts of chromosome $15 q$ were significantly associated with poor survival after CRS and HIPEC, which could represent future prognostic molecular biomarkers.

ACKNOWLEDGEMENTS Open access funding provided by Uppsala University. The authors thank Hanna Göransson Kultima, Amrei Binzer, Angeliki Pournara, and Malin Rosth at Science for Life Laboratory Uppsala, for their invaluable expertise in array analysis, and Tor Halle and Ulf Thunberg at the Clinical Pathology Unit, 
Uppsala, for help with FFPE tissue preparation and DNA extraction respectively.

FUNDING The study was funded by a dedicated grant from Uppsala University for SciLife research and the Swedish Cancer Society, Project Numbers 150767 and 150276.

DISCLOSURE The authors declare no conflicts of interest.

OPEN ACCESS This article is distributed under the terms of the Creative Commons Attribution 4.0 International License (http://crea tivecommons.org/licenses/by/4.0/), which permits unrestricted use, distribution, and reproduction in any medium, provided you give appropriate credit to the original author(s) and the source, provide a link to the Creative Commons license, and indicate if changes were made.

\section{REFERENCES}

1. Harmon RL, Sugarbaker PH. Prognostic indicators in peritoneal carcinomatosis from gastrointestinal cancer. Int Semin Surg Oncol. 2005;2:3.

2. Faron M, Macovei R, Goere D, Honore C, Benhaim L, Elias D. Linear relationship of peritoneal cancer index and survival in patients with peritoneal metastases from colorectal cancer. Ann Surg Oncol. 2016;23:114-9.

3. Harlaar NJ, Koller M, de Jongh SJ, van Leeuwen BL, Hemmer PH, Kruijff S, van Ginkel RJ, et al. Molecular fluorescence-guided surgery of peritoneal carcinomatosis of colorectal origin: a single-centre feasibility study. Lancet Gastroenterol Hepatol. 2016;1:283-90.

4. Massalou D, Benizri E, Chevallier A, Duranton-Tanneur V, Pedeutour F, Benchimol D, Bereder JM. Peritoneal carcinomatosis of colorectal cancer: novel clinical and molecular outcomes. Am J Surg. 2017;213:377-87.

5. de Cuba EM, Kwakman R, van Egmond M, Bosch LJ, Bonjer HJ, Meijer GA, te Velde EA. Understanding molecular mechanisms in peritoneal dissemination of colorectal cancer: future possibilities for personalised treatment by use of biomarkers. Virchows Arch. 2012;461:231-43.

6. Cancer Genome Atlas N. Comprehensive molecular characterization of human colon and rectal cancer. Nature. 2012;487:330-7.

7. Diep CB, Teixeira MR, Thorstensen L, Wiig JN, Eknaes M, Nesland JM, Giercksky KE, et al. Genome characteristics of primary carcinomas, local recurrences, carcinomatoses, and liver metastases from colorectal cancer patients. Mol Cancer. 2004;3:6.

8. Enblad M, Birgisson H, Wanders A, Skoldberg F, Ghanipour L, Graf W. Importance of absent neoplastic epithelium in patients treated with cytoreductive surgery and hyperthermic intraperitoneal chemotherapy. Ann Surg Oncol. 2016;23:1149-56.

9. Ronnett BM, Zahn CM, Kurman RJ, Kass ME, Sugarbaker PH, Shmookler BM. Disseminated peritoneal adenomucinosis and peritoneal mucinous carcinomatosis. A clinicopathologic analysis of 109 cases with emphasis on distinguishing pathologic features, site of origin, prognosis, and relationship to "pseudomyxoma peritonei”. Am J Surg Pathol. 1995;19:1390-408.

10. Sugarbaker PH. Peritonectomy procedures. Ann Surg. 1995;221:29-42.

11. Stephens AD, Alderman R, Chang D, Edwards GD, Esquivel J, Sebbag G, Steves MA, et al. Morbidity and mortality analysis of 200 treatments with cytoreductive surgery and hyperthermic intraoperative intraperitoneal chemotherapy using the coliseum technique. Ann Surg Oncol. 1999;6:790-6.
12. Foster JM, Oumie A, Togneri FS, Vasques FR, Hau D, Taylor M, Tinkler-Hundal E, et al. Cross-laboratory validation of the OncoScan(R) FFPE Assay, a multiplex tool for whole genome tumour profiling. BMC Med Genomics. 2015;8:5.

13. Iddawela M, Rueda O, Eremin J, Eremin O, Cowley J, Earl HM, Caldas C. Integrative analysis of copy number and gene expression in breast cancer using formalin-fixed paraffin-embedded core biopsy tissue: a feasibility study. BMC Genomics. 2017;18:526.

14. Skirnisdottir I, Mayrhofer M, Rydaker M, Akerud H, Isaksson A. Loss-of-heterozygosity on chromosome $19 \mathrm{q}$ in early-stage serous ovarian cancer is associated with recurrent disease. BMC Cancer. 2012;12:407.

15. Rasmussen M, Sundstrom M, Goransson Kultima H, Botling J, Micke P, Birgisson H, Glimelius B, et al. Allele-specific copy number analysis of tumor samples with aneuploidy and tumor heterogeneity. Genome Biol. 2011;12:R108.

16. North BV, Curtis D, Sham PC. A note on the calculation of empirical $\mathrm{P}$ values from Monte Carlo procedures. Am J Hum Genet. 2002;71:439-41.

17. Davison AC, Hinkley DV. Tests. In: Bootstrap Methods and their Application. Cambridge: Cambridge University Press; 1997. https://doi.org/10.1017/CBO9780511802843.

18. Andersen PK, Gill RD. Cox's regression model for counting processes: a large sample study. Ann Stat. 1982;10:1100-20.

19. Mayrhofer M, Kultima HG, Birgisson H, Sundstrom M, Mathot L, Edlund K, Viklund B, et al. 1p36 deletion is a marker for tumour dissemination in microsatellite stable stage II-III colon cancer. BMC Cancer. 2014;14:872.

20. Kleivi K, Lind GE, Diep CB, Meling GI, Brandal LT, Nesland $\mathrm{JM}$, Myklebost $\mathrm{O}$, et al. Gene expression profiles of primary colorectal carcinomas, liver metastases, and carcinomatoses. Mol Cancer. 2007;6:2.

21. Diep CB, Kleivi K, Ribeiro FR, Teixeira MR, Lindgjaerde OC, Lothe RA. The order of genetic events associated with colorectal cancer progression inferred from meta-analysis of copy number changes. Genes Chromosomes Cancer. 2006;45:31-41.

22. Ried T, Meijer GA, Harrison DJ, Grech G, Franch-Exposito S, Briffa R, Carvalho B, et al. The landscape of genomic copy number alterations in colorectal cancer and their consequences on gene expression levels and disease outcome. Mol Aspects Med. 2019;69:48-61.

23. Numata M, Oshima T. Significance of regenerating islet-derived type IV gene expression in gastroenterological cancers. World $J$ Gastroenterol. 2012;18:3502-10.

24. Wang H, Hu L, Zang M, Zhang B, Duan Y, Fan Z, Li J, et al. REG4 promotes peritoneal metastasis of gastric cancer through GPR37. Oncotarget. 2016;7:27874-88.

25. Vinson KE, George DC, Fender AW, Bertrand FE, Sigounas G. The Notch pathway in colorectal cancer. Int $J$ Cancer. 2016;138:1835-42.

26. Chu D, Zhang Z, Zhou Y, Wang W, Li Y, Zhang H, Dong G, et al. Notch1 and Notch2 have opposite prognostic effects on patients with colorectal cancer. Ann Oncol. 2011;22:2440-7.

27. Korchynskyi O, Landstrom M, Stoika R, Funa K, Heldin CH, ten Dijke P, Souchelnytskyi S. Expression of Smad proteins in human colorectal cancer. Int J Cancer. 1999;82:197-202.

28. Ewing GP, Goff LW. The insulin-like growth factor signaling pathway as a target for treatment of colorectal carcinoma. Clin Colorectal Cancer. 2010;9:219-23.

29. Carter SL, Cibulskis K, Helman E, McKenna A, Shen H, Zack T, Laird PW, et al. Absolute quantification of somatic DNA alterations in human cancer. Nat Biotechnol. 2012;30:413-21.

Publisher's Note Springer Nature remains neutral with regard to jurisdictional claims in published maps and institutional affiliations. 